\title{
Análises microbiológicas de polpas de açaí comercializadas na cidade de Araguari/MG
}

\author{
DOI: 10.47224/rm.v5i10.94
}

\author{
Letícia Viana Abadio \\ Ana Rose Silva \\ Laura Cristina Tibiletti Balieiro \\ Carlos Alberto de Oliveira \\ Mirian Ribeiro Moreira Carrijo
}

e-mail:vianaleticia453@gmail.com

\section{Resumo}

O açaí é muito comercializado em produtos alimentícios, o que requer extremo cuidado em sua manipulação. Assim, o presente trabalho objetivou, avaliar a qualidade microbiológica de polpas de açaí congeladas e comercializadas na cidade de Araguari/MG. Foram coletadas 10 amostras de açaí no período de setembro a outubro de 2019. Foram determinados o pH; Número Mais Provável de coliformes totais e termotolerantes (NMP/mL); Unidades Formadoras de Colônia de bolores e leveduras (UFC/g) e a presença de Escherichia coli pelo método do caldo seletivo "RapidHiColiformBroth". O pH médio das polpas foi 4,55 sendo confirmado a presença de bolores e leveduras em todas as amostras, com valores que variaram de 1 × 102 a 6,7 x 103 UFC/g, porém somente 3 estabelecimentos estavam em desacordo com a legislação (IN n.01, 07/01/2000 do MAPA). Para coliformes totais e termotolerantes; os valores foram de 3,6 x 100 a 4,3 x 101 NMP/mL em 5 a 6 amostras, mas todas ficaram dentro do padrão estabelecido (RDC n.12, 02/01/2001 ANVISA). Não houve presença de Escherichia coli. Com os resultados obtidos deve-se considerar que, é necessária uma vigilância mais rigorosa para conseguir a diminuição do risco de contaminação e a garantia da segurança alimentar dos consumidores.

Palavras-chave: Polpas de açaí. Análise microbiológica. Contaminação alimentar.

\section{Abstract}

Açaí is being widely commercialized in food products, which requires extreme care in its handling. Thus, this study aimed to evaluate the microbiological quality of frozen and commercialized açaí pulps in the city of Araguari / MG. 10 samples of açaí were collected from September to October 2019. The pH was determined; Most likely number of total and thermotolerant coliforms (NMP / mL); Colony Forming Units of molds and yeasts (UFC/g) and the presence of Escherichia coli by the selective broth method "RapidHiColiformBroth". The average $\mathrm{pH}$ of the pulps was 4.55 and the presence of molds and yeasts in all samples was confirmed, with values ranging from $1 \times 102$ to $6.7 \times 103$ CFU / g, however only 3 establishments were in disagreement with the legislation. (IN No. 01, 07/01/2000 of MAPA). For total and thermotolerant coliforms; the values were $3.6 \times 100$ to $4.3 \times 101 \mathrm{NMP} / \mathrm{mL}$ in 5 to 6 samples, but all were within the established standard (RDC n.12, 02/01/2001 ANVISA). There was no presence of Escherichia coli. With the results obtained, it should be considered that, stricter surveillance is necessary to achieve the reduction of the risk of contamination and the guarantee of food safety for consumers.

Keywords: $\quad$ Açai pulps. Microbiological analysis. Food contamination.

\section{INTRODUÇÃO}

O açaí é um pomo resultante de palmeiras da espécie Euterpe oleracea Martius, nativa da região
Amazônica, sendo o estado do Pará seu principal centro de distribuição natural. Os pomos são redondos e formados em cachos, porém seu consumo não ocorre na forma in natura, sendo necessário ser 
processado. Dos pomos do açaizeiro se extrai o vinho, polpa ou simplesmente açaí, como é conhecido na região, sendo consumido pela população brasileira em uma variedade de bebidas e preparações alimentares (FARIA et al., 2012).

Este é um alimento de alto valor calórico, com porcentagem elevada de gordura (lipídeos), e rico em proteínas e minerais, principalmente potássio e cálcio e, dentre as vitaminas, pode ser destacada a vitamina $E$, um antioxidante natural que atua na erradicação dos radicais. Do pomo se retira o óleo que possui ácidos graxos de boa qualidade, sendo $60 \%$ de monoinsaturados e $13 \%$ de poliinsaturados. Em relação as proteínas, possui teor maior que o leite $(3,50 \%)$ e o ovo $(12,49 \%)$, enquanto o perfil em aminoácidos é parecido com o do ovo. Pertencentes a família dos flavonoides, as antocianinas são consideradas pigmentos naturais, que são responsáveis pela cor do açaí. Também possuem função antioxidante, garantindo melhor circulação sanguínea, logo protegem o organismo contra o acúmulo de placas de depósito de lipídeos, que acarretam a formação de arteriosclerose (NOGUEIRA et al., 2005).

O açaí possui altas concentrações de açúcar, alta atividade de água, baixo $\mathrm{pH}$ e intensa visitação por insetos, se tornando um ótimo meio para se desenvolver uma grande variedade de microrganismos. Os bolores e leveduras se desenvolvem em uma larga faixa de $\mathrm{pH}$ fazendo com que estes microrganismos se tornem um dos principais agentes de degradação das frutas (ARAÚJO, 2015).

Nas regiões produtoras, a polpa de açaí é comercializada normalmente à temperatura ambiente, quando o seu consumo é imediato ou após certo período de refrigeração e, é congelada, quando o seu consumo se destina aos comércios distantes (YUYAMA et al., 2002).

A busca alimentar envolvendo o açaí aumentou significativamente nos últimos anos, em função de suas características nutritivas e energéticas. Seu consumo é mais frequente nas regiões sul e sudeste na forma congelada enquanto no norte e nordeste este fruto é consumido in natura. Há uma preocupação com a polpa congelada, pois somada a carga microbiana natural dos frutos, esta torna-se mais susceptível a contaminação proveniente das condições higiênico sanitárias vindas dos equipamentos, ambiente de processamento e dos manipuladores (MELLO; RESENDE, 2018).
De acordo com Souza e Gomes (2019), o açaí é favorável a contaminação de bactérias, como coliformes totais, coliformes termotolerantes, Escherichia coli, Salmonella sp., parasitas, fungos e leveduras. Os coliformes totais são formados por bactérias na forma de bastonetes gram-negativos, não esporuladas, aeróbios ou anaeróbios facultativos, sendo capaz de fermentar a lactose formando gás, em 24 a 48 horas a 35C. Já os coliformes termotolerantes possuem a mesma definição dos coliformes totais, porém para as bactérias que fermentam a lactose produz gás, em 24 horas a 44,5 - 45,5ㅇ. Cscherichia coli faz parte dos termotolerantes, mas é presente no trato intestinal do homem e animais homeotérmicos (SALES et al., 2015). Os fungos são considerados como eucariotas, sendo os patogênicos de duas formas: as formas filamentosas, os bolores, e as unicelulares, as leveduras. Os fungos filamentosos em decomposição de alimentos produzem metabólicos secundários, que são chamados de micotoxinas, a sua produção depende do crescimento fúngico, portanto pode ocorrer em qualquer época do crescimento, colheita ou estocagem do alimento. Os gêneros dos fungos mais comumente associados com toxinas que ocorrem, naturalmente, são Aspergillus, Penicillium e Fusarium (IAMANAKA et al., 2010).

Segundo o Ministério da Saúde (2001), as doenças transmitidas por alimentos (DTA's) são causadas pela ingestão de um alimento contaminado por um agente infeccioso específico, ou pela toxina por ele produzida, por meio da transmissão desse agente, ou de seu produto tóxico. É geralmente constituída de anorexia, náuseas, vômitos e/ ou diarreia, acompanhada ou não de febre, relacionada à ingestão de alimentos ou água contaminados. As DTA's podem ser causadas por: bactérias, vírus, parasitas, toxinas, príons, agrotóxicos, produtos químicos e metais pesados (BRASIL, 2016).

A segurança alimentar deve ser um quesito essencial, da colheita até a distribuição para o consumidor. Não há muitos dados referentes a qualidade microbiológica do açaí, mas com as condições do fornecimento atual nos estabelecimentos pequenos que estão em vários pontos das cidades fica comprovado à importância de avaliar a qualidade microbiológica dos produtos desde que a falha nessas condições higiênicos sanitárias pode se tornar um risco à saúde dos consumidores. A segurança alimentar é um problema de saúde pública, podendo gerar uma série de consequências, entre elas as DTA's (SILVA et al., 2016). 
Assim, o presente trabalho teve como objetivo, avaliar a qualidade microbiológica de polpas de açaí congeladas e comercializadas na cidade de Araguari/MG, através da análise de coliformes totais e termotolerantes, presença de Escherichia coli, contagem de bolores e leveduras e determinação de $\mathrm{pH}$.

\section{METODOLOGIA}

\subsection{Obtenção das amostras}

Foram coletadas 10 amostras de polpas de açaí pasteurizadas, em diferentes estabelecimentos comerciais alimentícios de Araguari/MG no período de setembro a outubro de 2019, e transportadas em caixas isotérmicas para o Laboratório de Microbiologia e Parasitologia, do Instituto Master de Ensino Presidente Antônio Carlos/ IMEPAC - Araguari (MG). As amostras foram separadas em duas partes em sacos estéreis, de maneira asséptica e transportadas em caixa isotérmica até o Laboratório de Biotecnologia Animal Aplicada na Universidade Federal de Uberlândia - UFU, para análise microbiológica de coliformes totais e termotolerantes; bolores e leveduras.

\subsection{Determinação do pH das amostras}

As amostras foram pesadas (10g) e diluídas em $90 \mathrm{~mL}$ de água destilada dentro da capela de fluxo laminar. Após o processo de homogeneização asséptica, a leitura do $\mathrm{pH}$ foi realizada utilizando o pHmetro digital de bancada (marca: LineLab, modelo: pH Pro). Foram realizadas 3 medições para cada amostra, sendo o valor final dado pela média aritmética simples.

\subsection{Preparo das amostras}

As amostras foram previamente descongeladas até atingir temperatura ambiente $\left(26^{\circ} \mathrm{C}\right)$, pesadas na proporção de $25 \mathrm{~g}$ e transferidas para Erlenmeyer com $225 \mathrm{~mL}$ de água peptonada estéril para iniciar a diluição das amostras.

\subsubsection{Análise de coliformes totais e termotolerantes}

Para análise dos coliformes totais e termotolerantes foi determinado o Número Mais Provável (NMP/mL) sendo utilizada a técnica dos tubos múltiplos, com três séries de três tubos em cada diluição $\left(10^{-1}, 10^{-}\right.$ $\left.{ }^{2}, 10^{-3}\right)$. Foi utilizado como meio presuntivo o caldo (Lauril Sulfato Triptose) com incubação a $35^{\circ} \mathrm{C}$, durante 48 horas. No teste confirmatório foi utilizado - caldo (Lactose Verde Brilhante bile 2\%) para coliformes totais, com incubação a $35^{\circ} \mathrm{C}$ por $24-48$ horas e caldo (EC) para coliformes termotolerantes com incubação a $44,5^{\circ} \mathrm{C}$, em banho-maria, por 24 horas. O NMP de coliformes totais e termotolerantes foi determinado mediante tabela de Hoskins, a partir do número de tubos positivos nas diferentes diluições empregadas.

\subsection{Análise de Escherichia coli}

Foi realizado incubação $\left(35-37^{\circ} \mathrm{C}\right)$ com o meio "RapidHiColiformBroth" (RHB), sendo repicados em placa de Petri, contendo ágar PCA e RHB por 48 horas. Os tubos continham caldo azul-esverdeado, os quais florescem na presença da lâmpada UV/366 nm. Também foi realizado o teste do indol, utilizando o reativo de Kovacs. Para esta reação os algodões presentes nos tubos apresentam coloração avermelhada, quando considerados positivos para $E$. coli.

\subsection{Identificação de bolores e leveduras}

Para quantificação de bolores e leveduras foi utilizado o método de plaqueamento em superfície. Para isso foram semeados $0,1 \mathrm{~mL}$ das diluições $10^{-1}, 10^{-2}, 10^{-3}$ em placas com o Agar Dicloran Rosa de Bengala Cloranfenicol (Agar $D R B C$ ). As placas foram incubadas a $25^{\circ}$ por 5 dias e as colônias contadas. Os resultados das contagens foram multiplicados, pela recíproca da diluição utilizada e os resultados registrados como unidades formadoras de colônias por mililitro da amostra (UFC) $\left.\mathrm{ml}^{-1}\right)$.

\section{RESULTADOS E DISCUSSÃO}

A tabela 1 demonstra os dados obtidos referentes à contaminação por coliformes totais, coliformes termotolerantes, presença de Escherichia coli, contagem para bolores e leveduras e valores médios de $\mathrm{pH}$ em amostras de polpas congeladas de açaí. 
$\mathrm{O} \mathrm{pH}$ médio obtido das polpas de açaí mostrou-se abaixo ao encontrado por Santos et al. (2008), que obteve o valor de 4,8 das polpas de açaí de PalmasTO. O estabelecimento 9 apresentou o $\mathrm{pH}$ abaixo do limite estabelecido (tabela 1 ), a qual recomenda um pH mínimo de 4,0 e máximo de 6,2 (RDC n.12, 02/01/2001 ANVISA). Sendo assim o estabelecimento está mais favorável à presença de fungos, comprometendo a segurança alimentar.

Segundo a Empresa Brasileira de Pesquisa Agropecuária - (EMBRAPA), o açaí é um fruto que possui baixa acidez, com pH aproximadamente de 4,0 a 6,2, o que favorece o crescimento de vários tipos de microrganismos, incluindo os patogênicos. Ele é um fruto que se deteriora rapidamente, pois ele é altamente perecível; sua vida útil é de poucas horas à temperatura ambiente e, no máximo, 12 horas sob refrigeração. A perecibilidade é advinda das características do fruto, como ausência de camada protetora da polpa (casca rígida), e à sua composição química.

$\mathrm{O} \mathrm{pH}$ é um dos principais fatores intrínsecos responsáveis pelo crescimento, sobrevivência ou destruição dos microrganismos, eles têm valores de pH mínimo, máximo e ótimo, no qual seu crescimento microbiano é máximo. Mudanças no $\mathrm{pH}$ do alimento pode propiciar a atividade microbiana. Estes microrganismos mudam conforme as exigências aos fatores de crescimento e à capacidade de utilizarem os vários substratos que compõem os alimentos. Para a multiplicação microbiana, esses nutrientes devem estar disponíveis: água, fonte de nitrogênio, fonte de carbono, vitaminas e sais minerais. Deste modo, dependendo do tipo de nutriente que compõe o alimento, consegue-se determinar o microrganismo que possuirá maiores possibilidades de se desenvolver, como por exemplo os bolores que possuem maior interesse na deterioração de alimentos ricos em carboidratos complexos (polissacarídeos) e também óleos e gorduras que sofrem ação de muitos bolores, leveduras e algumas bactérias (FORSYTHE, 2013

Todas as amostras apresentaram a presença de bolores e leveduras com valores que variaram de $1 \mathrm{x}$ $10^{2}$ a $6,7 \times 10^{3} \mathrm{UFC} / \mathrm{g}$, mas somente em 3 estabelecimentos $(7,8$ e 9$)$ os valores se apresentaram em desacordo com os estabelecidos pela legislação (IN n.01, 07/01/2000 do MAPA) (BRASIL, 2000). Os limites preconizados na legislação para bolores e leveduras são no máximo $5 \times 10^{3}$ UFC.g${ }^{1}$ para polpa in natura, congelada ou não, e $2 \times 10^{3}$ UFC. $g^{-1}$ para polpa conservada quimicamente e/ ou que sofreu tratamento térmico. Os bolores e leveduras conseguem se desenvolver em uma larga faixa de $\mathrm{pH}$ e isso faz com que estes microrganismos tornem um dos principais agentes de deterioração do alimento (SACCOL et al., 2006).

A presença de fungos e leveduras podem demostrar a possibilidade de práticas inadequadas durante a fabricação do açaí. Assim, é relevante e necessário o controle rigoroso da cadeia do frio, além da aplicação das boas práticas de fabricação, devido esses microrganismos poderem ser causadores da deterioração do produto. Ainda, devem ser observadas as boas práticas no decorrer do transporte e armazenamento do produto congelado, pois podem contribuir para sua contaminação pósprocessamento, por exemplo, pode haver estrago de embalagens abrindo-as e havendo quebra na cadeia do frio (CAYRES et al., 2017).

Quando há presença de bolores e leveduras, com resultados abaixo do máximo designado pela legislação são considerados normais, ou seja, não significativas em alimentos frescos e congelados. No entanto, quando há contagens elevadas, além de possuir aspecto deteriorante, possui risco à saúde pública devido à possível produção de micotoxinas por algumas espécies de bolores (SANTOS et al., 2008). Para evitá-los é necessário realizar o processo de descongelamento através da refrigeração. Os manipuladores devem receber treinamentos periódicos para a correta manipulação do alimento a fim de evitar tais contaminações (SACCOL et al., 2006).

No trabalho de Faria et al. (2012), foi analisado a qualidade microbiológica de polpas de açaí provenientes de doze estabelecimentos comerciais em Pouso Alegre-MG; verificaram a presença de bolores e leveduras em apenas um ponto de coleta, sendo os dados obtidos acima do permitido pela legislação $\left(1,1 \times 10^{4} \mathrm{UFC} / \mathrm{ml}\right)$, para as demais amostras, os resultados foram entre $0,5 \times 10^{1}$ e 8,4 $\mathrm{x}$ $10^{2} \mathrm{UFC} / \mathrm{ml}$. Entretanto, Santos et al., (2016) em análise microbiológica de polpas de açaí comercializadas na cidade de São Paulo-SP, encontraram a presença de duas espécies bacterianas (Escherichia coli e Enterobacter) e um terceiro microrganismo Serratia, sendo um importante agente causador de intoxicações alimentares.

Segundo Santos et al. (2016), a contaminação dos alimentos pode ter seu início na produção da matériaprima, durante a manipulação, pela má higienização dos equipamentos e/ ou pelo manipulador.

Os resultados para coliformes totais e termotolerantes, foram de $3,6 \times 10^{0}$ a $4,3 \times 10^{1}$ 
$\mathrm{NMP} / \mathrm{mL}$ em 6 e 5 amostras, respectivamente, mas todas ficaram dentro do padrão estabelecido (RDC n.12, 02/01/2001 ANVISA).

Tabela 1. Resultados das análises microbiológicas para $\mathrm{pH}$, coliformes totais e termotolerantes, bolores e leveduras e Escherichia coli .

\begin{tabular}{|c|c|c|c|c|c|}
\hline & $\mathrm{pH}$ & $\begin{array}{l}\text { Coliforme } \\
\text { totais } \\
\text { (NMP } / \mathrm{mL} \text { ) }\end{array}$ & $\begin{array}{c}\text { Coliforme } \\
\text { termotolerantes } \\
(\mathrm{NMP} / \mathrm{mL})^{2}\end{array}$ & $\begin{array}{c}\text { Bolores e } \\
\text { leveduras } \\
\text { (UFC/g) }\end{array}$ & $\begin{array}{l}\text { Pesquisa de E. coli } \\
\text { Ausência/presença }\end{array}$ \\
\hline Estabelecimento 1 & 4,58 & $2,3 \times 10^{1}$ & $2,3 \times 10^{1}$ & $8,0 \times 10^{2}$ & Ausência \\
\hline Estabelecimento 2 & 4,48 & $<0,3^{*}$ & $<0,3^{*}$ & $1,0 \times 10^{2}$ & Ausência \\
\hline Estabelecimento 3 & 4,78 & $<0,3^{*}$ & $<0,3^{*}$ & $1,0 \times 10^{2}$ & Ausência \\
\hline Estabelecimento 4 & 4,64 & $3,6 \times 10^{0}$ & $3,6 \times 10^{0}$ & $9,0 \times 10^{2}$ & Ausência \\
\hline Estabelecimento 5 & 4,61 & $4,3 \times 10^{1}$ & $2,3 \times 10^{1}$ & $1,1 \times 10^{3}$ & Ausência \\
\hline Estabelecimento 6 & 4,77 & $4,3 \times 10^{1}$ & $2,3 \times 10^{1}$ & $6,0 \times 10^{2}$ & Ausência \\
\hline Estabelecimento 7 & 4,49 & $<0,3^{*}$ & $<0,3^{*}$ & $2,9 \times 10^{3}$ & Ausência \\
\hline Estabelecimento 8 & 4,83 & $3,6 \times 10^{0}$ & $<0,3^{*}$ & $6,7 \times 10^{3}$ & Ausência \\
\hline Estabelecimento 9 & 3,79 & $<0,3^{*}$ & $<0,3^{*}$ & $2,8 \times 10^{3}$ & Ausência \\
\hline Estabelecimento 10 & 4,56 & $4,3 \times 10^{1}$ & $4,3 \times 10^{1}$ & $1,7 \times 10^{3}$ & Ausência \\
\hline Padrão & $\begin{array}{c}\text { Min 4,0 Max } \\
6,2\end{array}$ & - & Máx 1,0 x10 & Máx 2,0 x10 & Ausente \\
\hline
\end{tabular}

Fonte: os autores

A presença de coliformes na produção e/ ou manipulação de alimentos pode ser um indicativo de má higienização, quando o número de coliformes é elevado nos alimentos não quer dizer que foi contaminação direta, mas que não obteve higienização adequada em alguma etapa seja no transporte, higiene dos manipuladores ou acondicionamento inadequado. Sendo assim, são necessárias as boas práticas agrícolas para minimizar o risco de contaminação dos frutos e as boas práticas de fabricação para a obtenção do produto (polpa), assim o alimento terá qualidade e garantia de segurança para o consumidor (COHEN et al., 2011). Porém, estudo de Almico et al. (2018), os resultados apresentaram a necessidade de um controle maior dos órgãos fiscalizadores para que as polpas de açaí sejam ofertadas ao consumidor em boas condições higiênico-sanitárias e sem adulteração.

Em relação a avaliação nesse estudo de Escherichia coli, em todas as amostras analisadas, verificou a ausência deste microrganismo. Em semelhança aos estudos de Cayres et al. (2010) que verificaram a ausência de E. coli e Salmonella em 48 amostras analisadas de açaí tipo fino congeladas, não pasteurizadas e adquiridas do comércio popular da cidade do Rio de Janeiro-RJ.
No estudo realizado por Souza e Gomes (2019), na análise microbiológica de 4 amostras diferentes de polpa de açaí (A, B, C e D) das principais feiras livres na cidade de Porto Velho-RO, 3 apresentaram Coliformes Totais e Termotolerantes (exceto a amostra B). De acordo com os parâmetros estabelecidos pela Agência Nacional de Vigilância Sanitária (ANVISA) na Resolução RDC n¹2 de 2001, que estabelece o limite de $500 \mathrm{NMP} / \mathrm{mL}$ todas as amostras analisadas estão adequadas para consumo e dentro dos padrões legais vigentes.

Entretanto, no trabalho de Silva et al. (2016), foi avaliado a qualidade microbiológica de 20 amostras de "açaí na tigela" comercializadas em uma cidade do Oeste Paulista. Foi observado que as contagens variaram de no mínimo 2,38 $\pm 0,12$ UFC/g (Açaí com banana) a um máximo de 6,7 $\pm 0,00$ UFC/g (Açaí com morango). Além disso, foi observada uma variação nas contagens de bolores e leveduras de 2,30 $\pm 0,42$ log UFC/g (Açaí com banana) a um máximo de 5,87 \pm $0,02 \log \mathrm{UFC} / \mathrm{g}$ (Açaí com morango). Com os resultados obtidos neste trabalho foi possível observar um mínimo de contaminação por coliformes totais $>1100 \mathrm{NMP} / \mathrm{g}$. A análise da contaminação das amostras com Salmonella $s p$, coliformes 
termotolerantes e Escherichia coli apresentaram resultados negativos.

Muitos estudos relatam sobre as DTA's, segundo Jesus et al. (2018), as condições inadequadas para a manipulação dos alimentos acabam evidenciando o quanto é importante o cuidado ao manejar produtos como o açaí que é um fruto presente na mesa de muitas famílias como refeição principal.

Os surtos de DTA's crescem de maneira exponencial anualmente, além da escassez de conhecimento dos consumidores direcionado as boas práticas de manipulação do alimento. Mediante a este fato há um aumento nas pesquisas microbiológicas direcionadas ao âmbito alimentar (SANTOS et al., 2016). Segundo o estudo de Balbani e Butugan (2001), no qual foi realizado análises em produtos de vendedores ambulantes a fim de constatar se o alimento era seguro para o consumo, em SalvadorBA, os autores encontraram que $39,1 \%$ dos acarajés, $95,6 \%$ dos vatapás, $82,6 \%$ das saladas e $100 \%$ dos camarões secos estavam contaminados por coliformes fecais, $S$. aureus, Salmonella sp e clostridios. Já em São Paulo, analisou-se doces de amendoim (DA) e doces de leite (DL), dentre as contaminações havia fragmentos de insetos (DA: 60,7\% e DL: 58,6\%), ácaros (DA: 11,7\% e DL: 26,8\%) e pelos de roedor (DA:6,8\% e DL: 5,7\%) (BALBANI; BUTUGAN, 2001). As bactérias comumente relacionadas com surtos de intoxicação alimentar são Staphylococcus aureus e Salmonella sp (SANTOS et al., 2016).

Frente ao exposto, é possível notar a importância que os estudos microbiológicos em alimentos têm para o consumidor, a fim de evitar as DTA's, visto que é considerado um problema de saúde pública e apesar de existir vigilância sanitária requer medidas visando a melhoria na fiscalização para que o consumidor possa ter um alimento seguro.

4

\section{CONCLUSÕES}

Com os resultados obtidos deve-se considerar que, apesar do açaí ter tantos benefícios, trata-se de um alimento manipulado, sendo necessária uma vigilância rigorosa nesses estabelecimentos para conseguir a diminuição do risco de contaminação e a garantia da segurança alimentar dos consumidores.

Sendo assim, é necessário a realização de ações educativas como a adoção de programas de treinamentos eficientes e permanentes para os manipuladores de alimentos, aderindo as Boas Práticas de Manipulação, o sistema de Análise de
Perigos e Pontos Críticos de Controle, assim como as Boas Práticas Agrícolas, pois os resultados obtidos podem ser oriundos de possíveis contaminações desde a coleta da matéria-prima até o armazenamento inadequado. Por isso, são necessários manipuladores aptos e treinados controlando diariamente a temperatura do produto e verificando o armazenamento correto do mesmo em toda a cadeia de distribuição.

\section{REFERÊNCIAS}

ALMICO, J. D et al. Avaliação da qualidade microbiológica, físico-química e química de polpas de açaí (Euterpe oleracea Mart) pasteurizadas congeladas comercializadas em Aracaju-SE. Revista Brasileira de Higiene e Sanidade Animal. v.12, n.2, p. 156-168, 2018.

ARAÚJO, R. P. S. Avaliação da qualidade microbiológica de polpas de frutas comercializadas no município de Currais Novos/RN. 2015. $41 \mathrm{f}$. Trabalho de Conclusão de Curso - Instituto Federal de Educação, Ciência e Tecnologia do Rio Grande do Norte, Currais Novos, 2015.

BRASIL. Ministério da Agricultura, Pecuária e Abastecimento. Instrução Normativa no 01, de 07/01/00. Regulamento técnico geral para fixação dos padrões de identidade e qualidade para polpa de fruta. Diário Oficial da República Federativa do Brasil, Brasília, DF, Seção I, p.54-58, 10 jan. 2000.

BRASIL. Ministério da Saúde. Resolução RDC n.12, 02 de janeiro de 2001. Regulamento técnico sobre padrões microbiológicos para alimentos. Diário Oficial da União, 10 jan. 2001.

BRASIL. Ministério da Saúde. Surtos de Doenças Transmitidas por Alimentos no Brasil. 2016, 19 p.

BALBANI A. P. S; BUTUGAN O. Contaminação biológica de alimentos. Pediatria (São Paulo), p. 320328, 2001.

CAYRES, C. A. et al. Avaliação Microbiológica de Polpa de Açaí Congelada Comercializada na Cidade do Rio de Janeiro. In: II Simpósio em Ciência e Tecnologia de Alimentos. 1 을 Congresso do Instituto Nacional de Frutos Tropicais. 2010, Aracaju. Avanços em tecnologia de alimentos: anais. Aracaju: Universidade Federal de Sergipe, 2010, p. 10161019.

CAYRES, C. A. et al. Qualidade microbiológica de açaí industrializado. Embrapa Meio Ambiente-Artigo em 
periódico indexado (ALICE), Higiene Alimentar, v. 31 n. 268/269, p. 134-138, 2017.

COHEN, K. O. et al. Contaminantes microbiológicos em polpas de açaí comercializadas na cidade de Belém-PA. Revista Brasileira de Tecnologia, v. 5, n. 02, p. 524-530, 2011.

EMBRAPA. Empresa Brasileira de Pesquisa Agropecuária. Árvore do conhecimento Açaí. Disponível em:

https://www.agencia.cnptia.embrapa.br/gestor/acai Larvore/CONT000gbfbxyh002wx5ok07shnq9m/wsec k.html. Acesso em: 16 nov. 2019.

FARIA, M. et al. Determinação da qualidade Microbiológica de polpas de açaí congeladas comercializadas na cidade de Pouso Alegre MG. Alimentos e Nutrição Araraquara, v. 23, n. 2, p. 243-249, 2012.

FORSYTHE, S. J. Microbiologia da Segurança dos

Alimentos. 2a Ed. Porto Alegre: Artmed, 2013, 620 p.

IAMANAKA, B. T. et al. Micotoxinas em alimentos. Anais da Academia Pernambucana de Ciência Agronômica, v. 7, p. 138-161, 2010.

JESUS, L. M. S. et al. Avaliação microbiológica do açaí comercializado no bairro Santa Rita, Macapá-Amapá. Rev. Arq. Científicos (IMMES), v. 1, n. 2, p. 21-27, 2018.

MELLO, C. N; RESENDE, J. C. P. Avaliação microbiológica de vitaminas de açaí comercializadas na região do Barreiro, Minas Gerais. Sinapse Múltipla, v. 7, n. 1, p. 27-37, 2018.

NOGUEIRA, O. L. et al. Açaí: Sistemas de Produção 4. Belém: EMBRAPA Amazônia Oriental, 2005.

SACCOL, A. L. F. et al. Importância de treinamento de manipuladores em boas práticas. Disciplinarum Scientia: Ciências da Saúde, Santa Maria, v. 7, n. 1, p. 91-99, 2006.

SALES, W. B. et al. Ocorrência de coliformes totais e termotolerantes em pastéis fritos vendidos em bares no centro de Curitiba-PR. DEMETRA: Alimentação, Nutrição \& Saúde, v. 10, n. 1, p. 77-85, 2015. polpas de açaí comercializadas na cidade de São Paulo. RBAC, v.48, n.1, p. 53-7, 2016.

SANTOS, C. A. A. et al. Avaliação microbiológica de polpas de frutas congeladas. Ciência e Tecnologia de Alimentos, v. 28, n. 4, p. 913-915, 2008.

SILVA, S. R. et al. Avaliação microbiológica em amostras de "açaí na tigela" comercializados em uma cidade do Oeste Paulista. FAURG, Gramado/RS, 2016.

SOUZA, A. B. N.; GOMES, M. A. S. Análise microbiológica da polpa de açaí comercializada em feiras livres na cidade Porto Velho/RO. Revista Saber Científico, 2019.

YUYAMA, L. K. O. et al. Açaí (Euterpe oleracea mart.) e camu-camu (Myrciaria dubia (HBK) Mc Vaugh) possuem ação anti anêmica?. Acta amazônica, v. 32, n. 4, Manaus, p. 625-633, 2002. 